http://dx.doi.org/10.12795/RAA.2011.i01.08

\title{
DÍAZ, IBÁN (2010). Sevilla, cuestión de clase. Una geografía socialdela ciudad. Sevilla: Atrapasueños, 425 pp.
}

Javier Hernández Ramírez

Departamento de Antropología Social

Universidad de Sevilla

En pocos años las urbes europeas han sufrido una enorme transformación. A pesar de su cercanía en el tiempo, queda ya lejos la ciudad industrial sometida al ritmo incesante del trabajo fabril que imponía orden, imagen e identidad a toda la vida social. Esta ciudad fordista apenas es reconocible hoy en occidente. El radical cambio producido en los sistemas de acumulación y la dinámica de deslocalización productiva ha transformado en obsoletas las grandes factorías, las formas de vida y las culturas del trabajo asociadas a la actividad industrial. Paralelamente han emergido nuevas dinámicas que modifican la fisonomía física y social de las urbes. De un lado, la competencia que se desarrolla entre las ciudades que aspiran a formar parte de una red mundial de lugares estratégicos con el objetivo de ocupar una posición ventajosa en el mercado global y atraer inversores y turistas, para lo que ofertan una imagen aparentemente singular y llevan a cabo operaciones de maquillaje y remodelación urbana; y de otro, la aceleración y acentuación de los procesos de especialización territorial iniciados en la modernidad, que generan una geografía en la que cada barrio y sector urbano desarrolla una función específica. El resultado es una ciudad compartimentada en distintos territorios especializados que se amplían al ámbito metropolitano. Así la antigua zona obrera del casco histórico se 
gentrifica al convertirse en el ámbito preferente de sectores acomodados; los lugares donde se concentran las calles, monumentos y edificios más emblemáticos y con mayor valor simbólico se museifican y vacían de vida autóctona al servicio del turismo; los homogéneos barrios obreros de la periferia se transforman en heterogéneas zonas residenciales multiétnicas donde conviven inmigrantes con bajos niveles de renta y una población autóctona en regresión y envejecida; y en los espacios liberados de la actividad industrial o de operaciones de remodelación y ampliación urbana se emplaza una arquitectura neomonumentalista, que destaca por un diseño creativo o un gigantismo espectacular, que trata de mostrar una imagen innovadora y simbolizar la vitalidad de la economía de la ciudad y/o el éxito económico de empresas y compañías bancarias. El fenómeno, que algunos autores celebran frívolamente como el paso de la ciudad activa a la ciudad festiva, de la ciudad del trabajo a centro de deseo (Cazes, 1998), de la ciudad provinciana a la cosmopolita (Carrillo, 2006) tiene consecuencias trascendentales en la organización urbana, la distribución del vecindario, los usos del espacio, la protección del patrimonio cultural y afecta severamente a las condiciones de vida de amplios sectores de la población y a las formas de organización y repuesta de las asociaciones vecinales.

Comprender cómo estos procesos han operado y conformado una determinada morfología social en Sevilla constituye uno de los objetivos centrales de la obra de Ibán Díaz, profesor de geografía de la Universidad de Sevilla y activista social involucrado directamente dentro de lo que él mismo denominaría las luchas por lo común, es decir, el movimiento político de los centros sociales okupados y autogestionados (CSOA). Este compromiso social impregna todo el texto que aquí se reseña, ya que el propósito del mismo trasciende a una mera geografía descriptiva para centrarse en el estudio de las diversas organizaciones sociales que reaccionan ante los procesos de exclusión y polarización socio-espacial derivados de las dinámicas anteriormente señaladas y, en última instancia, alcanzar un marco analítico que permita fomentar la acción política, lo que constituye el segundo gran objetivo de la obra.

Desde sus primeras páginas, el autor declara su intención de superar el estudio de corte localista y asistencialista preocupado tan solo por la identificación de los problemas "de" Sevilla, para enfocar su atención en los problemas "en" Sevilla, es decir, por el análisis de las transformaciones sociales y espaciales producidas por el nuevo sistema de regulación. La perspectiva analítica adoptada permite situar adecuadamente la ciudad en el contexto global y así atender tanto al impacto de los procesos como las amenazas y oportunidades que se pueden derivar de estos cambios para la acción política. Esta opción metodológica convierte la obra en un ensayo crítico de geografía que trasciende el análisis localista de lo local. Lástima que en el interior del trabajo se incurra a veces en el localismo que se critica, pues es frecuente la mención de lugares y barrios o un acercamiento a sucesos concretos acaecidos en Sevilla que difícilmente podrá situar el lector no nativo o que no 
esté familiarizado con la ciudad. No obstante, habría que insistir en que este enfoque, que trata de articular las dinámicas globales y cómo se materializan en el ámbito local, es una de las principales aportaciones del trabajo.

La obra es una suma de artículos independientes escritos en distintos momentos, que el mismo autor denomina "libro compilación", y que adquieren relativa coherencia interna y cierta articulación gracias a la introducción en la que se presentan los objetivos e hipótesis que luego se abordan en los distintos capítulos. Se sostiene como hipótesis que, a finales del siglo XX, se produce en Sevilla una serie de transformaciones que van a incidir radicalmente en la morfología social y la estructura económica generando "una nueva geografía social" (pp. 14), cuyas características principales serían la polarización de la sociedad en clases antagónicas y la segmentación espacial de los ámbitos residenciales entre lugares recualificados como escenarios turísticos; barrios gentrificados, donde se produce una sustitución de población obrera tradicional envejecida por la que denomina burguesía asalariada; y barrios etnizados en los que se concentran inmigrantes como nuevos actores sociales. Esta estructura guía una obra compuesta por ocho capítulos en los que se adopta un enfoque heredero de los estudios urbanos sobre desigualdad social realizados entre otros por David Harvey $(1977,2004,2007)$ y Mike Davis (2003). Tras el primer capítulo, en el que se aborda el marco teórico general, los principales conceptos utilizados y los nuevos procesos de segregación urbana, y el segundo que se centra en la evolución de la ciudad en el siglo XX, los capítulos tercero al sexto analizan cada uno de los procesos mencionados (polarización, recualificación, etnización y gentrificación). Mientras que en el séptimo y el octavo se realiza una clasificación de las organizaciones de resistencia a estos procesos y una reflexión final sobre la construcción de un movimiento sociopolítico urbano “por lo común y contra la desposesión” (pp. 393).

En su radiografía urbana, el autor describe una ciudad polarizada o dual. Unos ámbitos caracterizados por la recualificación y la gentrificación, junto con la ciudad de la exclusión social y los barrios multiétnicos que se han convertido en el hábitat preferente de las oleadas de inmigrantes de países del sur. Ibán Díaz ilustra cómo en Sevilla, del mismo modo que en muchas metrópolis, el objetivo de posicionamiento en un marco de competencia global implica el desarrollo de estrategias de museificación, neomonumentalismo y celebración de megaeventos y espectáculos de masas con vocación planetaria. Pero a diferencia de otras aproximaciones que apuestan por estas iniciativas con el argumento de que las mismas sitúan a las ciudades en la escala planetaria y la modernidad, Ibán Díaz subraya las contradicciones sociales inherentes a dichas operaciones de rehabilitación. Eludiendo o dejando en un segundo plano la crítica al impacto paisajístico y estético que caracteriza a los grupos conservacionistas, el autor destaca que la cosmética museificadora, los nuevos monumentos y los grandes eventos que han caracterizado la acción pública en las últimas décadas responden a una estrategia política de autopromoción y modificación 
de la imagen urbana que pretende transformar la ciudad en una mercancía-lugar o en una ciudad-fetiche de acuerdo con los gustos que demandan los mercados globales. Pero para garantizar el nuevo uso contemplativo y lúdico propio de los turistas, esta nueva ciudad espectáculo se convierte en un lugar excluyente de los usos sociales del espacio que produce una arquitectura de la seguridad y del miedo (bunkerización) mediante la eliminación o cerramiento de espacios públicos, la video-vigilancia, la supresión de bancos o la intervención policial. Asimismo para potenciar el mercado inmobiliario en los barrios contiguos a esta ciudad museificada, los poderes públicos promueven una planificación urbanística que impulsa la renovación, incrementa el valor del suelo y excluye al vecindario tradicional, que es sustituido por profesionales y sectores de más renta que adquieren sus viviendas en propiedad, reduciendo la oferta de alquiler. En el otro polo de la ciudad describe los procesos de etnización que implican la incorporación de población inmigrante en determinados sectores, lo que genera una nueva morfología urbana definida por la segregación étnica y la concentración de distintas nacionalidades en zonas específicas. Es un territorio marcado por el miedo al otro y por las contradicciones que se producen entre distintas maneras de vivir la ciudad en un contexto de desempleo y precariedad laboral. Concluye la cartografía social de Sevilla con el estudio de los procesos de segregación socio-espacial, la generación por el mercado de zonas estigmatizadas y la incapacidad de la administración pública para intervenir en las causas estructurales que causan la desigualdad urbana.

La geografía trazada se apoya en una concepción marxista de la realidad en la que la clase social funciona como el principio de estructuración social determinante y se define por la posición ocupada por los sujetos en relación con la circulación y acumulación de capital. Desde este enfoque, la clase obrera es compleja, pero única, ya que se configura como una masa asalariada económicamente polarizada y culturalmente fragmentada "por cuestiones culturales" de etnicidad, capital humano, generación y renta. De acuerdo con lo anterior, los otros criterios de diferenciación social quedan subsumidos como epifenómenos y son considerados factores culturales que responden a coyunturas concretas dependientes de la única variable estructurante: la clase social. En esta perspectiva la participación de los individuos y grupos en relaciones sociales de producción y consumo semejantes y diferenciadas de otros grupos supone la generación de intereses, pautas de comportamiento y estrategias residenciales compartidas. La ciudad postindustrial se interpreta como una sociedad dual segregada territorialmente en grupos cuyo criterio central y determinante de diferenciación es la clase social. A nuestro juicio este enfoque dificulta el análisis de los complejos procesos sociales que se viven en la ciudad postindustrial y la comprensión de las distintas visiones y prácticas sociales existentes entre grupos sociales que participan de la misma clase social, pero que poseen diferentes culturas del trabajo o identidades étnicas. ¿Acaso las pautas de asentamiento y modos de vida de los inmigrantes extranjeros procedentes del Sur son atribuibles casi exclusivamente a contradicciones de clase? 
Este marco teórico es un punto de partida que, a lo largo de la obra, no es objeto de verificación empírica, debido al empleo de una metodología particular cuyo propósito es cartografiar la ciudad, es decir, elaborar una topografía social a partir de fuentes documentales básicas, entrevistas a informantes privilegiados y técnicas cuantitativas débilmente explicadas e ilustradas con gráficos, cuyo diseño en blanco y negro impide entender con claridad lo que se desea representar. La obra habría alcanzado mayor profundidad si se hubiera desarrollado un trabajo de campo etnográfico que abordara la lógica que subyace a las prácticas sociales y las estrategias de los distintos sectores sociales, grupos e instituciones. No parece suficiente el recurso a la entrevista y el empleo de un estilo casi periodístico que, en forma de crónica, relata hechos y procesos, y sobre los que posteriormente se llega a conclusiones.

Los problemas teóricos y metodológicos señalados dejan en el aire demasiadas cuestiones, cuyas respuestas permitirían comprender algunos de los procesos y conflictos que se viven en la ciudad. En este sentido, se echa de menos un análisis de los distintos grupos sociales, las relaciones que establecen entre ellos y con las administraciones públicas. Por ejemplo, respecto de los grupos inmigrantes el estudio de sus redes sociales, tradiciones, rituales, patrones de comportamiento, vínculos con las comunidades de procedencia, creencias y alianzas con otros grupos; en relación con las dinámicas de gentrificación hubiera sido interesante abordar, además de las causas que explican la movilidad espacial, las percepciones sobre los valores de la ciudad histórica, así como las respuestas de las poblaciones tradicionales y sus apreciaciones sobre las estrategias de embellecimiento y espectacularización. Por otro lado, el esfuerzo del autor por caracterizar los distintos ámbitos territoriales de la ciudad conduce a una cierta reificación de los grupos que en ella habitan, que son explicados más en términos de contenidos culturales separados que en cuanto a las relaciones que establecen con otros grupos e instituciones. En este sentido, hablar de ciudad etnizada o ciudad gentrificada, resalta una dinámica y unos sectores sociales, pero puede oscurecer determinados procesos y conflictos entre grupos, así como el carácter multiétnico de muchos barrios de la ciudad.

Una de las aportaciones más significativas del trabajo de Ibán Díaz es la clasificación que realiza de las organizaciones sociales anti-hegemónicas existentes en Sevilla. Este conglomerado de entidades se caracteriza por la fragmentación, la desarticulación y la ausencia de un discurso basado en proyectos unitarios y alternativos, y apoyados en narrativas coherentes. Por ello prefiere denominarlas, particularidades militantes antes que movimientos sociales. Este heterogéneo magma asociativo lo forman entidades minoritarias pero muy activas, que van desde las organizaciones vecinales que reaccionan ante procesos de degradación urbanística y social (asociacionismo vecinal clásico) y las que se oponen a la desaparición física y social de los barrios a los que representan (particularismo resistencial) pasando por las organizaciones patrimonialistas (activismo 
conservacionista) hasta las agrupaciones juveniles que promueven una acción directa dirigida a la colectivización de espacios privados tras su ocupación (luchas por lo común). Completa el cuadro, el estudio del asociacionismo vecinal conservador que protagoniza una acción comunitaria, excluyente y racista basada en el rechazo al diferente, la defensa de la propiedad privada y la insistencia en la inseguridad ciudadana. Aunque el trabajo no se basa en una etnografía, la experiencia acumulada por el autor como activista militante le permite retratar con agudeza la ideología de estos grupos, sus acciones y composición social, así como establecer relaciones entre tipo de particularismo, segregación social y localización espacial. No obstante, el esfuerzo de clasificación de las organizaciones supone una cierta cosificación de las militancias en grupos estancos compuestos por sujetos homogéneos en cuanto a niveles formativos y de renta cuando en la realidad empírica los grupos y las personas son mucho más permeables. Probablemente, una aproximación empírica a estas organizaciones hubiera permitido un acercamiento más exhaustivo a esta realidad asociativa y su dinámica interna.

No hay duda de que Sevilla, cuestión de clase es una obra que no pasará desapercibida. A pesar de sus limitaciones teórico-metodológicas, sus reflexiones, conceptos y conclusiones sobre la ciudad global y sobre Sevilla en particular, así como su propuesta de construcción de un movimiento social urbano integrador y anti-hegemónico, abren un camino que permite superar la estrecha visión localista de los procesos y pensar qué hacer y cómo hacer para alcanzar una sociedad más justa en estos tiempos postutópicos. 